\title{
Assessment of Vocabulary Learning Strategy of English Language Majoring Students: The Case of third Year
}

\author{
Habtamu Wakjira (M.Ed) Hana Dereje (B.A) \\ Department of English Language and Literature, Assosa University
}

\begin{abstract}
This study aimed at assessing third year English language and Literature department students' vocabulary learning strategies. The assessment was limited to 2010 E.C graduating class of English Language and Literature department students in Assosa University. Purposive sampling technique was used to collect data for the research. This was primarily because the researcher was teaching this class and have got an opportunity to personally experienced how the students had hardly working on with vocabulary. In addition, these students had taken many courses on vocabulary learning strategies and they were the ideal class to check if they have understood and mastered the necessary skills during their stay in the university. This research is a survey research type. It applied quantitative and qualitative research methodology. The research used both questionnaire and interview data collection tools. All the 22 students were considered as data source. The data gathering tools used to gather data from the respondent was questionnaire and semi structured interview questions. The questionnaire has 25 items categorized in to six thematic areas. All the distributed questionnaires were filled and returned. The returned questionnaires were tallied and tabulated. And then, the tabulated data were interpreted, analyzed and the data collected through the semi structured questions were narrated and conclusion was drawn. The study revealed almost all students were highly relied on using dictionary to support their new vocabulary learning whenever they come across new words that may limit the level of their comprehension. Many students failed to use the social strategy of vocabulary learning which really affects their tendency of comprehending the texts. In turn, their failure to use this strategy affects their classroom interactions with and among themselves in the classroom. Consequently, the researcher recommends English language learners need to figure out different vocabulary learning strategies and their importance to themselves and consciously utilize them during their language learning. In addition, all English language learners need to keep record of all the vocabulary learning strategies available in the field that helps them to which strategy is effective to use. Next, all English language learners need to identify which vocabulary learning strategy is more effective at the context in which they are in. Finally, noticing that all the vocabulary learning strategies have their own importance in facilitating his/her learning of the target language, the students should appropriately use the best vocabulary learning strategy that might help them get what they need.
\end{abstract}

Keywords: Vocabulary, learning, strategies, social strategy, context

DOI: $10.7176 /$ RHSS/9-7-01

Publication date: April $30^{\text {th }} 2019$

\section{Introduction}

The foreign language learning process is a significant event in the life of the learner attempting to learn a foreign language for various reasons in our country, and interest in exploring and highlighting its nature and impact on eventual foreign language proficiency spans many decades. Exploring English language learners' vocabulary learning strategies is a key aspect of foreign language learning (FLL) in order to provide useful insights into the English vocabulary learning process.

In the process of investigating and classifying Language Learning Strategy, some studies indirectly involve the strategies specifically applicable to vocabulary learning. Nevertheless, studies on Vocabulary Learning Strategy in the early stage tend to focus on a limited number of strategies, such as guessing from context (Gibbs, 2001) and certain mnemonics like the Keyword Method (Nito, 2004). More thorough and in-depth studies which look at Vocabulary Learning Strategy as a group are in need to contribute to a more comprehensive taxonomy of Vocabulary Learning Strategy (Schmitt 1997). Therefore, the present study attempted to investigate whether English language students apply different vocabulary learning strategies to succeed in their education.

Over the year, different approaches, methods and procedure, have been employed to help learners learn second language. In one period considerable attention was paid to teaching and teacher-oriented classes. Because the emphasis was on grammatical and paid to phonologic structures, the vocabulary needed to be relatively simple, with new words introduced only as they were needed to make the drill possible. The belief was that vocabulary would take care of itself once the students learnt the grammatical structures (Zare, 2010). The researcher observed the challenges of the students from the practical experience when offering different courses to regular classes, faced a lot of problems while helping student to understand the meanings of new words or terms in making meanings out of what they are learning. These problems are unable to generate ideas, having less word power, problems of meaning, and difficulties of understanding on the vocabulary they used in the reading 
comprehension. This problems motivated the researchers to conduct the study on the knowledge of students utilization of different vocabulary learning strategies on 2010 E.C third year English Language and Literature department students at Assosa university. The researcher has developed the following basic research question hence the research aimed to identify students' awareness in using English vocabulary learning strategies in order to facilitate their own English language learning in classroom.

\section{Materials and Methods}

In this study, quantitative research method was employed. The study was conducted on students' vocabulary learning strategies. The population of the study was 2010 E.C third year English language and literature department students in Assosa University. The total number of third year English language and literature department students were 22. Out of the 22 students 5 of them were male students and 17 of them were female students. All graduate students under the department were considered in the study. To collect the data from the population of the study two data collecting tools were used. The data collection tool used for this particular research were questionnaire and semi structured interview. The questionnaires were adopted from the scholars work. The questionnaires consisted 25 items. These questions were categorized in to six thematic areas for the analysis purpose. The first category of the questionnaire focused on students' skill of using individual item determination skill to decode the meaning of new words whereas the second category dealt with students' utilization of social learning strategy in learning new words. The third group worked on respondents' application of consolidation strategies, and the fourth category tried to check learners' habit of using memory strategies in order to tackle the meaning of the new words they find in their lessons. The next two categories identified students' ability using the cognitive and Meta cognitive strategies in their life time learning. After the quantitative data collection was preformed, it was analyzed according to the thematic category. Semi structured interview was also used to collect qualitative data from the respondents in order to supplement the data gained through questionnaire. The semi structured interview question focused on the thematic areas identified for the questionnaire part. The qualitative data was narrated qualitatively. Finally, interpretation was given based on the information obtained through data collection tools.

\section{DISCUSSIONS AND RESULTS}

Table 1 Descriptive Statistics of Strategy Use in Individual Item of Determination

\begin{tabular}{|c|c|c|c|c|c|c|c|c|c|c|c|}
\hline \multirow[b]{3}{*}{$\mathrm{NO}$} & \multirow[b]{3}{*}{ Items } & \multicolumn{10}{|c|}{ Degree of frequency } \\
\hline & & \multicolumn{2}{|c|}{ Always } & \multicolumn{2}{|c|}{ Often } & \multicolumn{2}{|c|}{ Sometimes } & \multicolumn{2}{|c|}{ Seldom } & \multicolumn{2}{|c|}{ Never } \\
\hline & & 4 & $\%$ & 3 & $\%$ & 2 & $\%$ & 1 & $\%$ & 0 & $\%$ \\
\hline 1 & $\begin{array}{l}\text { I use bilingual dictionary to help me translate } \\
\text { English words into my own mother tongue. }\end{array}$ & 11 & 50 & 4 & 18.2 & 4 & 18.2 & 3 & 13.6 & 0 & 0 \\
\hline 2 & $\begin{array}{l}\text { I use picture illustration in the text book to find } \\
\text { the word meanings. }\end{array}$ & 4 & 18.2 & 5 & 22.7 & 6 & 27.3 & 3 & 13.6 & 4 & 18.2 \\
\hline 3 & $\begin{array}{l}\text { I learn meaning of words by identifying its part } \\
\text { of speech. }\end{array}$ & 6 & 27.3 & 7 & 31.8 & 6 & 27.3 & 2 & 9.1 & 1 & 4.5 \\
\hline
\end{tabular}

As can be seen from the table $4: 1,11(50 \%)$ of the respondents replied that they always use bilingual dictionary in order to learn the meaning of new words they have come across in their reading/ learning. $4(18.2 \%)$ of the respondents often use the bilingual dictionary for getting the meanings of new word whereas $4(18.2 \%)$ of the students responded they sometimes use the bilingual dictionary. 3(13.6) students responded that they rarely use bilingual dictionary never use bilingual dictionary to tackle the meanings of new words. This issue was confirmed by the interview made with the respondents. To put it in the respondents own point "Frankly speaking, I really frustrate when the teacher asked the class students where I don't have the chance to check the bilingual dictionary." The other respondents explained how far all students are addicted to use dictionary even in the exam. "To be honest nowadays most students have loaded modern dictionary on their cell phones and try to use it during exam."

The second question presented to my respondent was to know whether they used picture illustration to find out the meanings of new words they have come across. Here, 4(18.2\%) of the students responded that they always use picture illustrations to support them get the meaning of the new words. $5(22.5 \%)$ of the students replied that they often use picture illustration to support them get the meaning they want. $6(27.3)$ of the respondents responded that they sometimes picture illustration to support them get the meaning they want. $3(13.6 \%)$ of the respondents said that they rarely use picture illustrations to help them find out the meaning of new word they are dealing with. $4(18.2 \%)$ of the responded that they never use the picture illustrations to find out the meanings of new words. None replied that they refrain from using bilingual dictionary.

The last questionnaire presented to the respondents under this category of vocabulary learning strategy aimed to find out if students have used knowledge of parts of speech to figure out the meaning of new words they might have come across during their schooling. $6(27.3 \%)$ respondents responded that they always use their 
knowledge of parts of speech to help them get the meaning of new words whereas $7(31.8 \%)$ students replied that they often use parts of speech to identify the meaning of new words. 6(27.3\%) students replied that they sometimes apply their knowledge of parts of speech to figure out the meanings of new words while $2(9.1 \%)$ students replies they rarely used parts of speech in order to get the meanings of new words whereas only $1(4.5 \%)$ students had replied that he/she never used the knowledge of parts of speech to get the meaning of new words.

From the above responses one can conclude that most of the students highly depend on using the bilingual dictionary in order to figure out the meaning of new words they have come across. Here, the high dependence on the bilingual dictionary highly affects the success of students' language learning through breaking the smooth flow of idea. Even from the responses for the three questions presented, one may conclude that the students have lacked consistency from one question to the next one.

The next table presents the respondents social connection strategy that they apply in their vocabulary development. This section presents four questionnaires to find out how far the students are using social knowledge to strengthen their vocabulary stock.

Table 2 Frequency Use in Individual Item of Social Strategies

\begin{tabular}{|c|c|c|c|c|c|c|c|c|c|c|c|}
\hline \multirow{3}{*}{$\begin{array}{l}\text { No. } \\
4\end{array}$} & \multirow{3}{*}{$\begin{array}{l}\text { Items } \\
\text { I ask my teacher to translate the new word into } \\
\text { my own language. }\end{array}$} & \multicolumn{10}{|c|}{ Degree of frequency } \\
\hline & & \multicolumn{2}{|c|}{ Always } & \multicolumn{2}{|c|}{ Often } & \multicolumn{2}{|c|}{ sometimes } & \multicolumn{2}{|c|}{ seldom } & \multicolumn{2}{|c|}{ never } \\
\hline & & 5 & 22.7 & 5 & 22.7 & 4 & 18.2 & 3 & 13.6 & 4 & 18.2 \\
\hline 5 & $\begin{array}{l}\text { I ask my teacher to put an unknown word into } \\
\text { a sentence to help me understand the word } \\
\text { meaning. }\end{array}$ & 7 & 31.8 & 7 & 31.8 & 2 & 9.1 & 3 & 13.6 & 3 & 13.6 \\
\hline 6 & $\begin{array}{l}\text { I ask my classmate for the meaning of new } \\
\text { words I have come across. }\end{array}$ & 9 & 40.9 & 4 & 18.2 & 6 & 27.3 & 4 & 18.2 & 4 & 18.2 \\
\hline 7 & $\begin{array}{l}\text { I know some new words when working in } \\
\text { group works. }\end{array}$ & 8 & 36.7 & 5 & 22.7 & 7 & 31.8 & & & 2 & 9.1 \\
\hline
\end{tabular}

Table 4.2 shows, 5(22.7\%) of the respondents replied that they always used to ask their teacher to translate the new word they find difficult in order to learn the meaning of that word they find difficult to add it to their vocabulary stock. Whereas $5(22.7 \%)$ of the respondents often ask their teacher for translation to getting the meaning of new word while $4(18.2 \%)$ of the study responded they sometimes ask their teacher for translation. $3(13.6 \%)$ students responded that they rarely used to ask their teacher to help them translate the new word to get the meaning of new words but $4(18.2 \%)$ of the students replied that they never ask the teacher to translate the new word into their mother tongue in order to learn the meaning of the new word(s).

The second question presented to the respondent was to ask the teacher to put unknown word into a sentence to find out the meaning of new word they have come across. Here, 7(31.8\%) of the students responded that they always asked the teacher to put the unknown word they get into a sentence to help them get the meaning of new words contextually. $7(31.8 \%)$ of the students replied that they often asked the teacher to support them get the meaning they want through the help of context. $2(9.1 \%)$ of the respondents responded that they sometimes asked the teacher to support them get the meaning the meaning of the new words by putting the new word in the sentence to help them guess the meaning of the words contextually. $3(13.6 \%)$ of the respondents said that they rarely asked the teacher to help them understand the meaning of new word they are dealing with through context. $3(13.6 \%)$ of the responded that they never asked the teacher to make a sentence using the new word to find out the meaning of the new word.

The third question aimed at digging out the habit of the respondents if they have habited asking their classmate in order to tackle the meaning of new words they did not come across before. $9(40.9 \%)$ of the students replied that they always asked their classmate to support them get the meaning of new word. $4(18.2 \%)$ of the students replied that they often asked their classmates to support them get the meaning the new words they did not know before. $6(27.3 \%)$ of the respondents responded that they sometimes asked their classmate to support them get the meaning they are not familiar with. 4(18.2\%) of the respondents said that they rarely asked their classmate to help them find out the meaning of new word they are dealing with. 4(18.2\%) of the responded they never asked their classmate to find out the meaning of new words .

The last questionnaire in this category of vocabulary learning strategy aimed to find out how students have used social strategies to figure out the meaning of new words they might have come across during their learning. $8(36.7 \%)$ respondents responded that they always use their knowledge of group works to help them get the meaning of new words whereas $5(22.7 \%)$ students replied that they often work in group to identify the meaning of new words. $7(31.8 \%)$ students replied that they sometimes applied their group work knowledge to figure out the meaning of new words while no body replied they rarely use group work knowledge in order to get new words whereas only $2(9.1 \%)$ students had replied that he/she never use working in group works to get the meaning of new words. From the above responses one can concluded that most of the students learn new words through social context vocabulary learning strategy. But what really manifested in the real classroom revealed in 
the first category is quite contradictory. The result from the interview part confirms that many students have no experience of applying the social vocabulary learning strategies. Even what the responses of the students revealed is that this is the first time they have heard that social strategy is there to learn new vocabulary entries.

Table 4.3 is going to address the respondents' habit of using the new words they have come across through practicing it in actual context in order to retain the meanings of the new words for longer. The researcher raised three basic questions in order to find out what the respondents say about the practice they have made in their life. Table 4.3 Frequency Use in Individual Item of Consolidation

\begin{tabular}{|c|c|c|c|c|c|c|c|c|c|c|c|}
\hline \multirow[t]{3}{*}{ No. } & \multirow[t]{3}{*}{ Items } & \multicolumn{10}{|c|}{ Degree of frequency } \\
\hline & & \multicolumn{2}{|c|}{ Always } & \multicolumn{2}{|c|}{ Often } & \multicolumn{2}{|c|}{ Sometimes } & \multicolumn{2}{|c|}{ Seldom } & \multicolumn{2}{|c|}{ Never } \\
\hline & & & $\%$ & & $\%$ & & $\%$ & & $\%$ & & $\%$ \\
\hline 8 & $\begin{array}{l}\text { I practice the new English language } \\
\text { word(s) in group work activities. }\end{array}$ & 9 & 40.9 & 5 & 22.7 & 4 & 18.2 & 3 & 13.6 & 1 & 4.5 \\
\hline 9 & $\begin{array}{l}\text { I ask native speaker for help, whenever I } \\
\text { have got the chance to ask them. }\end{array}$ & 4 & 18.2 & 5 & 22.7 & 3 & 13.6 & 4 & 18.2 & 6 & 27.3 \\
\hline 10 & $\begin{array}{l}\text { I learn words about the culture of } \\
\text { English language speaking countries. }\end{array}$ & 2 & 9.1 & 3 & 13.6 & 5 & 22.7 & 6 & 27.3 & 6 & 27.3 \\
\hline
\end{tabular}

As one can see from the table 4.3, 9(40.9\%) of the respondents replied that they always practiced the new vocabulary words they have faced for the first time in group work activities in order to get familiar with the meaning of the new words they have come across in that activity with their group mates. $5(22.7 \%)$ of the respondent said they often practiced the new vocabulary words they have faced for the first time in group work for getting the meaning of new word whereas $4(18.2 \%)$ of the students responded they sometimes practiced the new vocabulary words they have faced for the first time in group work activities. $3(13.6 \%)$ students responded that they rarely practiced in group whenever they come across new words and $1(4.5 \%)$ of the students replied that they never practiced the new vocabulary words they have faced for the first time in group to tackle the meaning of new words.

The second question presented to the respondent was to see whether they used to ask whenever and wherever they have come across native speaker to find out the meaning of new words they have come across. Here, $4(18.2 \%)$ of the student responded that they always asked native speaker to support them get the meaning of new words. $3(13.6 \%)$ of the respondents responded that they sometimes asked native speaker to support them get the meaning of the new word they do not know before. $4(18.2 \%)$ of the respondents said that they rarely asked native speaker to help them find out the meaning of new word they are dealing with. $6(27.3 \%)$ of the responded that they never asked native speaker to find out the meaning of new words.

The last questionnaire presented to the respondents under this category of vocabulary learning strategy aimed to find out if students have used the culture of English language speaking countries to figure out the meaning of new words they might have come across. $2(9.1 \%)$ respondents responded that they always study the culture of English language speaking countries to help them get meaning of new words whereas 3(13.6\%) students replied that they often study the culture of English speaking countries to identify the meaning of new words. 5(22.7\%) students replied that they sometimes apply their knowledge about the culture of speaking countries to figure out the meaning of new words while $6(27.3 \%)$ students replied they rarely study the culture of English speaking countries in order to get the meaning of new words wherever only $6(27.3 \%)$ students had replied that he/she never study the culture of English language speaking countries to get the meaning of new words.

From the above responses one can conclude that most of the students practice the meaning of the new word in group activities in order to figure out the meaning of new words they have come across.

Table 4 works on the respondents' habit of using memory strategy to retain the meaning of new words they have come across.

Table 4 Frequency Use in Individual Item of Memory

\begin{tabular}{|c|c|c|c|c|c|c|c|c|c|c|c|}
\hline \multirow[t]{3}{*}{ No. } & \multirow[t]{3}{*}{ Items } & \multicolumn{10}{|c|}{ Degree of frequency } \\
\hline & & \multicolumn{2}{|c|}{ Always } & \multicolumn{2}{|c|}{ often } & \multicolumn{2}{|c|}{ Sometimes } & \multicolumn{2}{|c|}{ Seldom } & \multicolumn{2}{|c|}{ Never } \\
\hline & & & $\%$ & & $\%$ & & $\%$ & & $\%$ & & $\%$ \\
\hline 11 & $\begin{array}{l}\text { I write a new word in a sentence so that I can } \\
\text { remember it. }\end{array}$ & 3 & 13.6 & 6 & 27.3 & 9 & 40.9 & 3 & 13.6 & 1 & 4.5 \\
\hline 12 & I repeatedly study a spelling of new word. & 7 & 31.8 & 6 & 27.3 & 4 & 18.2 & 3 & 13.6 & 2 & 9.1 \\
\hline 13 & I use physical action when learning new words. & 3 & 13.6 & 4 & 18.2 & 5 & 22.7 & 4 & 18.2 & 6 & 27.3 \\
\hline 14 & I speak words out loud when studying. & 1 & 4.5 & 6 & 27.3 & 3 & 13.6 & 3 & 13.6 & 9 & 40.9 \\
\hline
\end{tabular}

From the table $4.4,3(13.6 \%)$ of the respondents replied that they always practice the meaning of the new word(s) by writing the spelling of the new word in order to remember the meaning of new words they have come across in their reading. $6(27.3 \%)$ of the respondents often practice the meaning of the new word(s) by writing the 
spelling of the new word(s) for getting the meaning of new word(s) and retaining it for longer whereas $9(40.9 \%)$ of the students responded they sometimes practice the meaning of the new word(s) by writing the spelling of the new word(s) for getting the meaning of new word(s) and retaining it for longer. 3(13.6\%) students responded that they rarely sometimes practice the meaning of the new word(s) by writing the spelling of the new word(s) for getting the meaning of new word(s) and retaining it for longer and $1(4.5 \%)$ of the student replied that they never sometimes practice the meaning of the new word(s) by writing the spelling of the new word(s) for getting the meaning of new word(s) and retaining it for longer.

The second question, students replied to, was aimed to study how much students practice learning the meanings of new word(s) through its spelling to find out the meaning of new words they come across. Here, $7(31.8 \%)$ of the students responded that they always study the spelling of the new word(s) to support them get the meaning of new words. $6(27.3 \%)$ of the students replied that they often focused on studying the spelling of the new word(s) to support them get the meaning of the new word they are searching for. 4(18.2\%) of the respondents responded that they sometimes study the spelling of the new word(s) to support them get the meaning they need. $3(13.6 \%)$ of the respondents said that they rarely study the spelling of the new word(s) to help them find out the meaning of new words they are dealing with. 2(9.1\%) of the responded that they never study the spelling of the new word(s) to find out the meaning of new words.

The third question presented to the respondent was to check whether they use physical action to find out the meaning of new words they have come across. Here $3(13.6 \%)$ of the students responded that they always use physical action to support them get the meaning of new words. 4(18.2\%) of the students replied that they often use physical action to support them get the meaning they want. $5(22.7 \%)$ of the respondent responded that they sometimes use physical action to support them get the meaning they need. $4(18.2 \%)$ of the respondent said that they rarely use physical action to help them find out the meaning of new word they are dealing with. $6(27.3 \%)$ of the responded that they never use the physical action to find out the meaning of new words.

The last questionnaire presented to the respondents under this category of vocabulary learning strategy aimed to find out if students have used speaking a loud to figure out the meaning of new words they might have come across during their learning. $1(4.5 \%)$ respondents responded that they always practice speaking aloud to themselves to help them get the meaning of new words whereas 3(13.6\%) students replied that they often practice speaking aloud to themselves to help them get the meaning of new words. $6(27.3 \%)$ students replied that they sometimes practice speaking aloud to themselves to help them get the meaning of new words while $3(13.6 \%)$ students applied that they rarely practice speaking aloud to themselves to help them get the meaning of new words whereas $9(40.9 \%)$ students had replied that he/she never practices speaking aloud to themselves to help them get the meaning of new words.

From the above responses one can conclude that most of the students practice speaking aloud to themselves the spelling of the new word(s) they find in their English language learning in order to figure out the meaning of new words they have come across.

Table 5 below discusses respondents' utilization of cognitive strategy in their vocabulary development.

Table 5 Frequency Use in Individual Item of Cognitive strategy

\begin{tabular}{|c|c|c|c|c|c|c|c|c|c|c|c|}
\hline \multirow[t]{3}{*}{ No. } & \multirow[t]{3}{*}{ Items } & \multicolumn{10}{|c|}{ Degree of frequency } \\
\hline & & \multicolumn{2}{|c|}{ Always } & \multicolumn{2}{|c|}{ Often } & \multicolumn{2}{|c|}{ Sometimes } & \multicolumn{2}{|c|}{ Seldom } & \multicolumn{2}{|c|}{ Never } \\
\hline & & & $\%$ & & $\%$ & & $\%$ & & $\%$ & & $\%$ \\
\hline 15 & I repeatedly practice new words. & 6 & 27.3 & 4 & 18.2 & 4 & 18.2 & 2 & 9.1 & 6 & 27.3 \\
\hline 16 & $\begin{array}{l}\text { I write a new word on a flash card so I can } \\
\text { remember it. }\end{array}$ & 3 & 13.6 & 1 & 4.5 & 5 & 22.7 & 4 & 18.2 & 9 & 31.8 \\
\hline 17 & I learn words by listening to vocabulary CDs. & 3 & 13.6 & 1 & 4.5 & 4 & 18.2 & 4 & 18.2 & 10 & 45.5 \\
\hline 18 & $\begin{array}{l}\text { I record vocabulary from English sound track } \\
\text { movies in my notebook }\end{array}$ & 3 & 13.6 & 2 & 9.1 & 3 & 13.6 & 5 & 22.7 & 9 & 31.8 \\
\hline 19 & $\begin{array}{l}\text { When I try to remember a word, I write or say } \\
\text { it repeatedly. }\end{array}$ & 8 & 36.4 & 3 & 13.6 & 5 & 22.7 & 2 & 9.1 & 4 & 18.2 \\
\hline 20 & $\begin{array}{l}\text { I make vocabulary cards and take them with } \\
\text { me wherever I go. }\end{array}$ & 4 & 18.2 & 3 & 13.6 & 5 & 22.7 & 4 & 18.2 & 6 & 27.3 \\
\hline
\end{tabular}

From the table $4.5,6(27.3 \%)$ respondents responded that they repeatedly practiced the meaning of the new word(s) in order to capture the meaning of new words they come across in their English language learning. $4(18.2 \%)$ of the respondent often repeatedly practiced the meaning of the new word(s) for retaining the meaning of new words whereas $4(18.2 \%)$ of the students responded they sometimes repeatedly practiced the meaning of the new word(s). 2(9.1\%) students responded that they rarely repeatedly practiced and $6(27.3 \%)$ of the students replied that they never repeatedly practiced the meaning of the new word(s) to extract the meaning of new word(s).

The second question was set to investigate whether students use flash card to find out the meaning on new 
words they have come across. Here $3(13.6 \%)$ of the students responded that they always use flash card to support them get the meaning of the new words. $1(4.5 \%)$ of the students replied that they often use flash card to support them get the meaning they want. 5(22.7\%) of the respondents responded that they sometimes use flash card to support them get the meaning they need. $4(18.2 \%)$ of the respondents said that they never use flash card to remember the meaning of the new words.

The third question appeared to check whether students listen to vocabulary CDs to find out the meaning of new words they have come across. Here $3(13.6 \%)$ of the students responded that they always listened to vocabulary CDs to support them get the meaning of the new word(s). 1(4.5\%) of the students replied that they often listened to vocabulary CDs to support them get the meaning they want. $4(18.2 \%)$ of the respondents responded that they sometimes listened to vocabulary CDs to support them get the meaning they want. 4(18.2\%) of the respondents said that they rarely listened to vocabulary CDs to help them find out the meaning of new word they are dealing with. $10(45.5 \%)$ of the responded that they never listened to vocabulary CDs to find out the meaning of new words.

The forth question was set forward if students were accustomed to keep record of new vocabulary to use them as a means to learn the meaning of the new word(s) in English language learning. Here, 3(13.6\%) of the students responded that they always keep records of the new word(s) to help them learn the meaning of the new words. $2(9.1 \%)$ of the students replied that they often keep record of new vocabulary to use them as a means to learn the meaning of the new word(s) in English language learning. 3(13.6\%) of the respondents responded that they sometimes keep record of new vocabulary to use them as a means to learn the meaning of the new word(s) in English language learning.. 5(22.7\%) of the respondents said that they rarely keep record of new vocabulary to use them as a means to learn the meaning of the new word(s) in English language learning. $9(31.8 \%)$ of the responded that they never keep record of new vocabulary to use them as a means to learn the meaning of the new word(s) in English language learning.

The fifth question set forth if students try to remember the meaning of the new word(s) either by writing them on their notebook or soy it orally. Here, $8(36.4 \%)$ of the students responded that they always write or repeatedly say it orally the meaning of the new word(s) in order to remember the meaning of the new word(s). $3(13.6 \%)$ of the student replied that they write or repeatedly say it orally the meaning of the new word(s) in order to remember the meaning of the new word(s). 5(22.7\%) of the respondents responded that they sometimes write or repeatedly say it orally the meaning of the new word(s) in order to remember the meaning of the new word(s). $2(9.1 \%)$ of the respondents said that they rarely write or repeatedly say it orally the meaning of the new word(s) in order to remember the meaning of the new word(s). $4(18.2 \%)$ of the respondents responded that they never write or repeatedly say it orally the meaning of the new word(s) in order to remember the meaning of the new word(s).

The last questionnaire presented to respondents under this category of vocabulary learning strategy aimed to find out if student make and keep vocabulary cards with them to figure out the meaning of new words. Here, $4(18.2 \%)$ respondents responded that they always make and keep vocabulary cards with them to help them get the meaning of new words whereas $3(13.6 \%)$ students replied that they often make and keep vocabulary cards with them to identify the meaning of new words. $5(22.7 \%)$ students replied that they sometimes make and keep vocabulary cards with them in order to get the meaning of new words whereas $6(27.3 \%)$ students replied that he/she never makes and keeps vocabulary cards with him/her to get the meaning of new words.

From the above responses one can conclude that most of the students try to make and keep vocabulary cards with them in order to help them remember the meaning of new words they have come across.

The last table works on the meta-cognitive strategy of vocabulary learning strategy.

Table 6Frequency Use in Individual Item of Meta-cognitive strategy

\begin{tabular}{|c|c|c|c|c|c|c|c|c|c|c|c|}
\hline \multirow[t]{2}{*}{ No. } & \multirow[t]{2}{*}{ Items } & \multicolumn{10}{|c|}{ Degree of frequency } \\
\hline & & \multicolumn{2}{|c|}{ Always } & \multicolumn{2}{|c|}{ Often } & \multicolumn{2}{|c|}{ Sometimes } & \multicolumn{2}{|c|}{ Seldom } & \multicolumn{2}{|c|}{ Never } \\
\hline 21 & I listen to English songs and news. & 6 & 27.3 & 3 & 13.6 & 6 & 27.3 & 4 & 18.2 & 3 & 13.6 \\
\hline 22 & I memorize word from English magazines. & 6 & 27.3 & 1 & 4.5 & 4 & 18.2 & 6 & 27.3 & 5 & 31.8 \\
\hline 23 & $\begin{array}{l}\text { I review my own English vocabulary cards for } \\
\text { reviewing my vocabulary knowledge before the } \\
\text { next lesson starts. }\end{array}$ & 6 & 27.3 & 6 & 27.3 & 6 & 27.3 & 1 & 4.5 & 3 & 13.6 \\
\hline 24 & $\begin{array}{l}\text { I do not worry very much about the difficult } \\
\text { words found when reading or listening, I pass } \\
\text { them. }\end{array}$ & 4 & 18.2 & 5 & 22.7 & 2 & 9.1 & 4 & 18.2 & 7 & 31.8 \\
\hline 25 & $\begin{array}{l}\text { I use on line exercise to test my vocabulary } \\
\text { knowledge. }\end{array}$ & 4 & 18.2 & 2 & 9.1 & 7 & 31.8 & 5 & 22.7 & 4 & 18.2 \\
\hline
\end{tabular}

As can be seen from the table 4.6,6(27.3\%) of the respondents replied that they always listened to songs and news in order to learn the meaning of new words they have come across. $3(13.6 \%)$ of the respondents often 
listened to songs and news for getting the meaning of new words whereas $6(27.3 \%)$ students responded they sometimes listened to songs and news. $4(18.2 \%)$ of the students replied that they rarely listened to songs and news and $3(13.6 \%)$ of the students replied that they never listened to songs and news to know the meaning of new words.

The second question was set forward to testify if students are memorizing the meaning of new word(s) they have got from magazines. Here, $6(27.3 \%)$ of the students responded that they always memorized the meaning of the new word(s) they have got from magazines to support them get the meaning of new words. $1(4.5 \%)$ of the students replied that they often memorize the meaning of the new word(s) they have got from magazines to support them get the meaning of the new word they need. $4(18.2 \%)$ of the respondents responded that that they sometimes memorize the meaning of the new word(s) they have got from magazines to support them get the meaning they want. $6(27.3 \%)$ of the respondents said that they memorize the meaning of the new word(s) they have got from magazines to support them get the meaning of the new word they need . 5(22.7\%) of the respondents that they never memorize the meaning of new word(s) they have got from magazines.

The third question is presented to the respondents if students review their vocabulary knowledge before the next lesson starts. 6(27.3\%) of the students responded that they always review the meaning of the new word/vocabulary they have already learned before the next day lesson starts to support them familiarized themselves to the meaning of the new word(s) they have identified. get the meaning of new words. $6(27.3 \%)$ of the student replied that they often review the meaning of the new word/vocabulary they have already learned before the next day lesson starts to support them familiarized themselves to the meaning of the new word(s) they have identified. $6(27.3 \%)$ of the respondents responded that they sometimes review the meaning of the new word/vocabulary they have already learned before the next day lesson starts to support them familiarized themselves to the meaning of the new word(s) they have identified. $1(4.5 \%)$ of the respondents said that they rarely review the meaning of the new word/vocabulary they have already learned before the next day lesson starts to support them familiarized themselves to the meaning of the new word(s) they have identified. 3(13.6\%) of the responded that they never review the meaning of the new word/vocabulary they have already learned before the next day lesson starts to support them familiarized themselves to the meaning of the new word(s) they have identified.

The forth question was presented to the respondents if they escape looking for the meaning of the new word(s) considering that it may not affect the comprehension as a whole. Here, 4(18.2\%) of the students responded that they do always escape searching the meaning of difficult word(s) when they find it in their reading considering that they could infer the meaning from the context. 5(22.7\%) of the students replied that they often escape searching the meaning of difficult word(s) when they find it in their reading considering that they could infer the meaning from the context. $2(9.1 \%)$ of the respondents responded that they do sometimes escape searching the meaning of difficult word(s) when they find it in their reading considering that they could infer the meaning from the context. $4(18.2 \%)$ of the respondents said that they worried and do not skip the meaning of the new words. $7(31.8 \%)$ of the responded that they highly worried and do not skip the meaning of the new words.

Finally from the above response one can conclude that most of the students fail to skip the meaning of the difficult words. They stick to search for their meaning from other sources to minimize their level of misunderstanding the text, but this would affect the flow of idea. Based on the analyzed data, the following conclusions were drawn: Most students rely on using dictionary to support their language learning whenever they come across new words that may determine the message of the text that they are reading or dealing with. When it comes to the social strategy of vocabulary learning, many students failed to use the social strategy of vocabulary learning which really affects their tendency of comprehending the message of the texts as a whole. In turn their failure to use this strategy affects their classroom interactions with and among the peers and/or teacher in the classroom and/or outside the class room context. To the contrary the respondents responded that they use consolidation strategy very well. But that contradicts with the idea that they did not interact in the classroom. The other point worth mentioning is that students focus on memorizing the words they found difficult/ new. The students highly depend on trying to remember the meaning of the new word(s) in order to figure out the meaning of new words they have come across. Here, the high dependence on trying to remember highly affects the success of students' language learning.

Based on the finding of the study, the following recommendations are forwarded: English language learners need to figure out the vocabulary learning strategies and their importance to themselves and consciously utilize them during their language learning. All English language learners need to keep record of all the vocabulary learning strategies available in the field. All English language learners needed to identify which vocabulary learning strategy is more effective and efficient at the context in which they are in; noticing that all the vocabulary learning strategy's importance they need to capitalize their advantage. 


\section{Reference}

Gibbs, J. (2001). Tribes: A new way of learning and being together. Windsor, CA: Center Source Systems.

Nito, R. (2004). Vocabulary \& ESP: Teaching Business Vocabulary. Retrieved 25 $5^{\text {th }}$ October 2017, from http://www.scribd.com/doc/46984761/ESP

Zare, P. (2010). An investigation in to language learning strategy use and gender among Iranian undergraduate language learners. World science journal, 11(10), 1236-1247. 